\title{
World Health Organization and emergency health: if not now, when?
}

In light of the recent Ebola epidemic, Francesco Checchi and colleagues argue that the World Health Organization's response to health emergencies is not fit for purpose and put forward six proposals to reform WHO's crisis response

Francesco Checchi senior humanitarian health lead ${ }^{12}$, Ronald J Waldman president ${ }^{34}$, Leslie F Roberts professor ${ }^{5}$, Alastair Ager director ${ }^{56}$, Ramin Asgary clinical assistant professor ${ }^{7}$, Marie T Benner senior health adviser ${ }^{8}$, Karl Blanchet lecturer ${ }^{2}$, Gilbert Burnham professor ${ }^{9}$, Emmanuel d'Harcourt senior health director ${ }^{10}$, Jennifer Leaning director ${ }^{11}$, Moses B F Massaquoi national Ebola case manager ${ }^{12}$, Edward J Mills senior epidemiologist ${ }^{13}$, Rachel T Moresky director, sidHARTe programme ${ }^{514}$, Preeti Patel senior lecturer ${ }^{15}$, Bayard Roberts director ${ }^{16}$, Michael J Toole deputy director $^{1718}$, Bradley Woodruff adjunct associate professor ${ }^{195}$, Anthony B Zwi professor of global health and development ${ }^{20}$

\footnotetext{
${ }^{1}$ Humanitarian Technical Unit, Save the Children, London, UK; ${ }^{2}$ Faculty of Public Health and Policy, London School of Hygiene and Tropical Medicine, London, UK; ${ }^{3}$ Doctors of the World USA, New York, USA; ${ }^{4}$ Global Health Department, Milken Institute School of Public Health, George Washington University, Washington, DC, USA; ${ }^{5}$ Heilbrunn Department of Population and Family Health, Mailman School of Public Health, Columbia University, New York, USA; ${ }^{6}$ Institute for Global Health and Development, Queen Margaret University, Edinburgh, UK; ${ }^{7}$ Department of Population Health, School of Medicine, New York University, USA; ${ }^{8}$ Malteser International, Cologne, Germany; ${ }^{9}$ Department of International Health, Bloomberg School of Public Health, Johns Hopkins University, Baltimore, USA; ${ }^{10}$ International Rescue Committee, New York, USA; ${ }^{11}$ François-Xavier Bagnoud Center for Health and Human Rights, Harvard School of Public Health, Boston, USA; ${ }^{12}$ Ministry of Health \& Social Welfare, Monrovia, Liberia; ${ }^{13} \mathrm{Global}$ Evaluative Sciences, Vancouver, Canada; ${ }^{14}$ College of Physicians and Surgeons, Columbia University, New York, USA; ${ }^{15}$ Department of War Studies, King's College London, London, United Kingdom; ${ }^{16} \mathrm{ECOHOST}$ - the Centre for Health and Social Change, London School of Hygiene and Tropical Medicine; ${ }^{17}$ Burnet Institute, Melbourne, Australia; ${ }^{18}$ Department of Epidemiology and Preventive Medicine, Monash University, Melbourne, Australia; ${ }^{19}$ Department of Global Health, Rollins School of Public Health, Emory University, Atlanta, USA; ${ }^{20}$ Health, Rights and Development (HEARD@UNSW), School of Social Sciences, University of New South Wales, Sydney, Australia
}

Human transmission of Ebola virus began in Guinea in December 2013, but inadequate surveillance and alert systems - characteristic of fragile states ${ }^{1}$ - delayed its recognition until March 2014. ${ }^{2}$ The World Health Organization has acknowledged it was ineffective during this critical early phase. ${ }^{3}$ Its Guinea office may have slowed down the response, ${ }^{4}$ while headquarters, fearing political and economic repercussions for countries affected, delayed declaring an international emergency until August 2014. ${ }^{5}$ The epidemic has caused at least 11300 deaths from Ebola, ${ }^{6}$ unquantified indirect excess mortality, and severe societal effects. ${ }^{7}$ The outbreak may not have been preventable, but its calamitous overspill was a quintessential failure of surveillance and containment. This failure has spurred various analyses of the global emergency health response system. ${ }^{9}{ }^{10}$ Various groups have formulated recommendations, including those set up by the United Nations secretary general, the Overseas Development Institute, ${ }^{11}$ the United States Institute of Medicine, ${ }^{12}$ Harvard University and the London School of Hygiene and Tropical Medicine (LSHTM) ${ }^{13}$ and WHO itself (the Ebola interim assessment panel). ${ }^{14}$

WHO is mandated to lead the Global Health Cluster (the global humanitarian system's main mechanism for coordinating health agencies' response to crises except refugee scenarios), support member states and non-state organisations in crisis preparedness and response, provide surge resources in emergencies, establish and disseminate technical standards, enforce the international health regulations (IHR) for managing health emergencies, and report attacks on health workers. ${ }^{15}$

While a process to reform WHO more generally has been ongoing since 2010, the Ebola epidemic has hastened calls to improve WHO's crisis response functions. ${ }^{16}$ A January 2015 
resolution ${ }^{17}$ of the organisation's executive board requests changes beginning January 2016. WHO has appointed an external advisory group to help formulate reforms. ${ }^{18}$ Here, as field practitioners and academics specialised in public health during crises, we recommend improvements to WHO's crisis response functions based on our experience and a non-systematic literature review of previous attempts at WHO reform. Though in this article we focus on WHO, we concur with others that many organisations (including other UN agencies, non-governmental organisations, governments, public health and research institutions) involved in epidemic preparedness, surveillance, response, and research and development must also evolve. ${ }^{11} 1319{ }^{20}$ While others have concentrated on epidemics, we take an all hazard perspective, recognising the large caseload of natural disasters (175 million people affected in $\left.2015^{21}\right)$ and armed conflict (172 million in $2013^{22}$ ), and their frequent overlap with epidemics. ${ }^{23}$

\section{What is actually wrong with WHO?}

The Ebola epidemic was the culmination of multiple instances, mainly undocumented, of WHO underperformance in crises. The box summarises recent examples, partially based on our direct observations. These examples delineate six stand-out problems, as discussed below.

\section{Prioritisation of political over technical considerations}

WHO's emergency response framework ${ }^{32}$ sets guidelines for managing new emergencies. However, its current version is arguably too focused on process rather than action and does not attribute authority to WHO when governments or other bodies are responding inappropriately. WHO's leadership of the Global Health Cluster provides a legitimate avenue for establishing sector leadership and coordination, though this approach relies on agencies' voluntary participation. The International Health Regulations provide instruments to deal with the inter-country dimensions of large epidemics, though they ascribe little authority to WHO to enforce technical recommendations. Improvements to the regulations, including earlier triggers for smaller outbreaks and incentives for countries to report and comply, have been recommended, ${ }^{20}$ and the regulations are under review.

Constitutionally, WHO is governed by member states, with senior managers at headquarters, regional, and country offices appointed with the approval of national ministers of health. ${ }^{933} 34$ While preventing hegemony by powerful stakeholders, this political dependency has degenerated into a culture that rewards protocol over substance; caution over courage; hierarchy over competence; conservatism in estimating problems; and obfuscation of evidence that might challenge relations with governments or donors. Public health considerations are often sidelined, ${ }^{35}$ and in high stakes situations such as Ebola virus disease and severe acute respiratory syndrome (SARS) epidemics, or state based conflict, political conditioning of WHO's response at country level often drives decision making at higher levels of the organisation. This is a reversal of the power structure required to respond to complex emergencies and obstructs WHO's role of brokering data collection, analysis, and dissemination.

WHO's tendency to maintain the status quo ${ }^{36}$ is not exceptional: many organisations become subservient to their own bureaucracy and political pressures. WHO, however, stands out for its inability to overcome these obstacles in times of crisis.

\section{Non-meritocratic human resources approach, with little reference to crisis response competencies}

WHO replaced all three country representatives in Guinea, Liberia, and Sierra Leone as the Ebola response was scaled up, indicating that key staff who should kickstart the organisation's emergency responses in the field are often unsuited. ${ }^{37} \mathrm{WHO}$ does not necessarily reward or promote based on merit, and staff performance management is constrained by the often short duration of staff contracts. Many senior positions are filled through informal political appointments.

Moreover, technical, managerial, and soft leadership competencies are not sufficiently considered during hiring and professional development of staff who oversee the response to crises (such as country representatives). ${ }^{36}$ Internal bureaucracy required to hire staff, or second people from other agencies, also curtails emergency responses.

\section{Aloofness from civil society partners and neglect of sector coordination and leadership functions}

WHO has traditionally prioritised its relationship with governments over that with civil society (non-governmental organisations, academic groups, professional associations), and headquarter, regional, and country staff with roles in managing crises (particularly epidemics) often have insufficient understanding of the international humanitarian architecture. ${ }^{4} 19$ There is an unresolved tension between WHO's conflicting mandates of supporting governments, and coordinating and leading the health sector during crises, particularly when governments are a party to conflict or obstruct the response.

Three areas have suffered from this neglect. Firstly, WHO has not sufficiently taken up sector leadership and coordination and is often perceived by non-governmental partners as a conduit for political agendas. WHO's leadership of the Global Health Cluster (set up in 2005) has been inadequate. Until 2014, only one headquarter staff member was dedicated to the cluster secretariat, and most of the 24 activated field clusters are inadequately staffed. Key areas of work (cluster coordinator training, roll-out of epidemiology and information management tools, raising cluster funding) have progressed slowly. Other UN agencies (Unicef, the World Food Programme, UNHCR) are more amenable to collaboration with civic society and have been more successful at leading and coordinating field operations. For example, clinical management of rape has primarily been tackled by the Global Protection Cluster, led by UNHCR, despite this being a health intervention.

Secondly, WHO has not played a major role in developing standards and policy for crises, though this normative function is arguably its principal strength in other areas of work. Such normative work should include developing a stronger evidence base for the health related technical standards of Sphere (the most widely used guidance for humanitarian interventions $)^{38}$ and other guidelines, which currently mostly reflect expert opinion. Similar problems exist with the "process standards" setting out expected actions at different stages of an emergency, including preparedness and recovery or mitigation. This role has partly been filled by other agencies, particularly Médecins Sans Frontières and the US Centers for Disease Control and Prevention. Building the requisite capacity of emergency response agencies and staff at the scale required to tackle 


\section{Examples of past WHO underperformance}

Northern Uganda, 2005- In June-July 2005, WHO and the Ministry of Health jointly conducted a survey ${ }^{24}$ of health conditions in overcrowded, underserviced camps where about 1.2 million people displaced by conflict with the Lord's Resistance Army lived. The survey showed very high rates of death and abduction. The report was rejected by the Ugandan government, and pro-government media suggested methodological flaws and data fabrication. WHO not only failed to defend the survey's findings but also impeded its publication in peer reviewed journals ${ }^{25}$

Zimbabwe, 2005-06- Following the 2005 elections in Zimbabwe, the government implemented "Operation Murambatsvina" to forcibly evict at least half a million urban dwellers mostly from opposition supporting slums in Harare, then home to the WHO Regional Office for Africa. Government officials justified the operation ${ }^{26}$ but humanitarian organisations reported alarming health effects and increasing food insecurity. ${ }^{27}$ An unpublished survey by Johns Hopkins University found that mortality in the affected population increased by about $60 \%$ in the year after displacement, mostly attributable to reduced HIV service. No record of WHO highlighting the plight of those displaced was found, and the agency had minimal involvement in assisting affected communities. One of the survey investigators was asked for mortality data by WHO staff in Geneva, who expressed frustration with WHO Harare for insisting that no information was available

Sri Lanka, 2009-The last stage of armed conflict between the Sri Lankan government and the Liberation Tigers of Tamil Eelam in March-May 2009, resulted in a concentration of trapped combatants and civilians on a narrow peninsula, with undocumented casualties from indiscriminate bombing. Survivors were held in camps for weeks by the Sri Lankan government. WHO maintained a minimal presence in the camps and generated no information on the public health situation, despite reports of a high death rate and poor water and sanitation conditions.$^{28}$ The regional WHO office did not request assistance from headquarters, and even discouraged staff in Geneva from offering support. Human rights abuses, widely known to have occurred, were not documented

Haiti, 2010 - In the days following the massive 2010 earthquake, when agencies began to flood into Haiti and technical coordination and leadership staff were most needed, the WHO country representative prevented headquarters staff from deploying to support the country office, for unknown reasons. WHO's response accelerated only after the director general insisted that an officer be appointed to fulfil WHO's responsibilities as health cluster coordinator. The slow action contributed to a delayed health assessment and prevented effective coordination of the numerous, variably professional agencies and medical groups intervening across the country

Horn of Africa, 2013 - In May 2013, polio virus was detected in Somalia for the first time in six years, and soon afterwards in Kenya and Ethiopia. By year's end, 217 cases were identified in the three countries. WHO's response involved two regional offices-Africa and Eastern Mediterranean. In October 2013, the independent monitoring board of the Global Polio Eradication Initiative praised the leadership shown by the Eastern Mediterranean director but noted that at the field level, the response was poorly coordinated and lacked urgency, with key positions remaining unfilled. The board's report concluded that "the response in the Horn of Africa could not be described as a robust response to a public health emergency of global importance"29

Syria, 2013-14-As of January 2013, about four million Syrians were living in opposition controlled or disputed territory, with growing public health needs. Turkey was the main access point for these populations, and also the base for most humanitarian agencies. WHO still formally acting in assistance to the Damascus Ministry of Health, was warned not to offer any support to opposition areas. A WHO suboffice was opened in Turkey, but solely to assist Syrian refugees in Turkey; staff almost never attended coordination meetings for work inside Syria organised by non-governmental organisations, even when a polio outbreak was detected in opposition areas ${ }^{30}$ As late as mid-2015, despite a UN resolution authorising the provision of formal assistance, WHO had not substantially strengthened its Turkey team and played a minimal role in supporting public health interventions in opposition held areas of Syria

South Sudan, 2013-14-WHO did not react publicly to the killing of patients in hospital beds, with looting and burning of hospitals, during armed conflict in December 2013 and February 2014. Instead, it focused mainly on reporting disease outbreaks ${ }^{31}$

Central African Republic, 2013-14-During the acute phase after a coup, collapse and widespread looting of the health system, and outbreaks of ethnic conflict, WHO did not substantially reinforce its country office, and a single, part-time staffer served as health cluster coordinator. Essential information management activities, including coordination matrices and epidemic disease surveillance, were delayed by months and surveillance covered only the capital, Bangui. Public health strategic planning was slow and non-transparent, and critical issues such as vaccination strategy and payment of health workers to return to work were left unresolved

multiple emergencies at once, however, has been globally neglected.

Thirdly, WHO has been timid in promoting health standards and quality control of crisis responses, though it has no formal enforcing authority. The Sphere project and other initiatives have tried to shift emergency response from a philanthropic (whereby any charitable act is helpful and not to be questioned) to a rights based model, but this transformation is incomplete. There is no formal professional certification of individuals or organisations and little recourse for people who are denied access to or provided with inappropriate services. As an exception, the current WHO emergency medical teams project to certify, standardise, and coordinate international medical groups deploying into natural disasters has enhanced the quality of recent surgical responses in Nepal and the Philippines. This project merits consideration as a model for ensuring that agencies and individuals do not operate without regulation, oversight, or enforcement.

\section{Lack of internal and external accountability}

Accountability to beneficiaries is increasingly emphasised in humanitarian practice. ${ }^{39} \mathrm{WHO}$, however, sees itself as accountable to and providing technical assistance to governments, even those with dubious legitimacy. ${ }^{4}$ Although WHO's performance is overseen by member states and, specifically, its executive board, these governance arrangements do not enable in-depth monitoring of crisis performance; this would require objective metrics and systematic evaluations by independent experts.

Whereas most humanitarian agencies have internal monitoring and evaluation teams and frameworks, WHO has limited mechanisms or incentives for evaluating itself objectively and tackling underperformance. Its headquarters is institutionally averse to effecting change in the regions despite disbursing general funds to them,${ }^{40}$ possibly because regional offices can block central influence on countries. ${ }^{41}$ Generally, WHO's management has discouraged transparency and admission of fault, exemplified in May 2015 by the self censorship of an unusually candid statement of responsibilities for the Ebola disaster, which was replaced by a heavily sanitised version within hours of publication. ${ }^{42}$ This tendency undermines opportunities for learning that are fundamental for self improvement. Admittedly, external observers, including the media, have not always generated constructive, actionable criticism of WHO.

\section{Problems with current structure}

Over the past decade WHO headquarters, particularly its humanitarian and epidemic divisions, has experienced ongoing restructure and reform ${ }^{33} 43$ with no observable leap in performance. Nevertheless, the current split between teams working on epidemic and pandemic control and those focusing on armed conflicts and disasters (which are better linked to the 
wider humanitarian architecture) is widely seen as unhelpful and is being removed at headquarters through the creation of a single outbreaks and health emergencies division. ${ }^{13} 1645$ Moreover, WHO's crisis response structure differs in the headquarters, regions, and countries, precluding a fully unified approach.

\section{Insufficient flexible funding for crisis functions}

The reduction of its core, unrestricted funding, cited by WHO as a reason for its low performance during the Ebola epidemic, reflects donors' increasingly vertical approach but also low donor confidence in WHO's ability to manage funds responsibly. ${ }^{33}{ }^{46}$ Shrinking core funding and staff cuts have impeded strategic planning and timely response. ${ }^{413}$ Instead of engaging with WHO to demand greater performance in crises in exchange for adequate, flexible funding, donors have broadly withdrawn interest and support, or sponsored non-WHO solutions like UNAIDS and the Global Fund for AIDS, Tuberculosis and Malaria.

\section{Six proposals for reform}

There is no single recipe for improvement nor a clear encouraging precedent. The past two decades have seen several ineffective attempts at WHO reform. ${ }^{43}{ }^{44} 478$ We believe that any reform will fall short of desirable outcomes unless the problems listed above are explicitly tackled, ${ }^{12}$ guided by a clear plan with objectives and expected outcomes at country, regional, and headquarters level. Broad measures, with which we largely concur, have already been recommended by the executive board, ${ }^{17}$ WHO's Ebola interim assessment panel, ${ }^{14}$ and others. ${ }^{11} 131619$ Aside from restructuring WHO headquarters, the current reform process seems to be focusing on topics (the financing of a $\$ 100 \mathrm{~m}$ emergency fund; the establishment of a global health emergency workforce) that are secondary to more fundamental changes.

The table $\Downarrow$ lays out six proposals for reforming WHO in relation to the critical problems identified above. Aspects of these proposals would doubtlessly encounter resistance and carry transactional costs, with a foreseeable period of turmoil. However, a conservative, more cosmetic approach would probably leave $\mathrm{WHO}$ at risk of even further reputational damage and dismemberment ${ }^{13}$ and populations exposed to substandard responses.

Incisive reforms now may be less expensive in absolute terms than maintaining the status quo (particularly considering the cost of poorly controlled emergencies such as Ebola, and the inefficiency of multiple WHO-like global health institutions). Indeed, we argue that the $\$ 100 \mathrm{~m}$ health emergency fund (only about $2 \%$ of total humanitarian funding for Ebola alone in west Africa as of August $2015^{49}$ ) does not reflect a real need and is unlikely to be spent efficiently; instead funds should be earmarked for refreshing staffing of critical posts and creating a pool of technical experts within WHO and partner agencies to fill leadership and coordination roles in emergencies, backed up by a well resourced professional development plan.

Not all parts of WHO's crisis response are dysfunctional. The Pan-American Health Organization (PAHO), also known as WHO's Americas Regional Office (AMRO), has a tradition of effective response to disasters, facilitated by more streamlined governance. WHO's Western Pacific Regional Office (WPRO) has overseen substantive responses to recent disasters in the Philippines. Both these regional offices have supported countries' emergency preparedness. WHO does groundbreaking work on mental health in emergencies, has recently established a functional cholera vaccine stockpile, and its emergency medical team project appears to be succeeding. Numerous experienced specialists in epidemics and other hazards work across the organisation. Clearly, a nuanced approach is needed to preserve what works well. Our proposals are not aimed at strengthening regional and country offices other than through professional development. Transferring authority and resources back to these offices is a desirable next stage in reform but will require major investments to improve their governance and management.

\section{Governance of WHO and its reform}

While the appointment of an external advisory body is welcome, WHO needs to go further in establishing transparency and oversight of the reform process. We propose that an external, independent governance committee be established for the new all hazards, outbreaks, and health emergencies division, composed primarily of people with minimal institutional allegiances (unlike the current advisory committee) and strong expertise in public health in emergencies or organisational management. This committee could be modelled on the independent monitoring board of the Global Polio Eradication Initiative, credited with improving oversight and accountability for that programme. ${ }^{50}$ It should independently appraise and validate WHO's reform proposals. A work plan with clear milestones should be agreed, containing conditions for release of further funding and, if reform falls greatly short of commitments, the option of entrusting crisis related functions to a new entity outside of WHO, with WHO contributing in a diminished capacity. The external committee should provide ongoing strategic management of the all hazards division (table), thereby safeguarding WHO from internal reticence to change.

As reform moves forward, WHO's main influencers-that is, its member states and principal donors-need to revise their relationship with the organisation, investing more resources in effective, real time governance and performance evaluation while simultaneously releasing proportionally more unrestricted funding to the organisation and empowering WHO's managers to focus on evidence based crisis responses, not political relations, as recommended by the Harvard-LSHTM panel. ${ }^{13} \mathrm{~A}$ constitutional change, reducing WHO's dependency on member states or allowing WHO in specific crisis situations to report solely to the UN, may be required to enshrine such a shift.

Similarly, civil society agencies should show greater willingness to engage with WHO and coordination mechanisms like the Global Health Cluster, freeing up resources to bolster WHO's staffing. In turn, greater involvement of civil society should be seen as an indicator of improved WHO performance.

\section{Conclusion}

In 1994, ineffective coordination and delayed response to the influx of about one million Rwandan refugees into camps in Tanzania and the Democratic Republic of the Congo contributed to some of the highest death rates ever measured in humanitarian settings. ${ }^{51}$ This disaster resulted in historic initiatives to professionalise the humanitarian sector, including the Sphere standards. ${ }^{38}$ Two decades later, the failure to control the Ebola epidemic in its early manageable phase may be a watershed of comparable importance.

The Ebola response has highlighted the need for many agencies and governments to urgently upgrade their capability to 
intervene in all types of crises. However, such improvements will struggle to attain their potential if the world's coordinating and technical leadership body remains unchanged. Indeed, if WHO cannot be reformed to allow it to occupy this pre-eminent position, some other multilateral entity must be allowed to assume it.

We believe that an effective, empowered WHO is a far better solution for global health governance, and for public health coordination and leadership in emergencies, than a multiplicity of partly overlapping entities, not all recognised by governments and at greater risk of becoming subservient to the most powerful governments and donors. To become the world's chief healer in times of crisis, WHO needs to consent to major surgery. The thousands dead because of the uncontained Ebola epidemic in west Africa stand silent witness to the human cost of delayed, politically constrained use of available public health data, coordination, and means of response. A radical reform of WHO cannot be delayed any further.

Contributors and sources: FC, RJW, and LFR wrote the paper. All other authors critically revised the paper and reviewed successive drafts. All authors have specific expertise and academic interests in public health in emergencies, and all have worked for WHO or interacted closely with the organisation both in the field and at head office. We based our analysis and recommendations on our direct experience of $\mathrm{WHO}$, a non-systematic review of published literature on WHO reform over the past 20 years, and, for some authors, discussions held recently on WHO reform with relevant stakeholders within $\mathrm{WHO}$ and in other panels or groups examining this topic. All authors wrote in a personal capacity, and their opinions do not necessarily represent those of the institutions with which they are affiliated. FC is the guarantor of the article.

Competing interests: We have read and understood BMJ policy on declaration of interests and declare the following: $\mathrm{FC}$ worked for WHO $\mathrm{HQ}$ as a consultant and employee between 2005 and 2009 and served on four WHO technical expert panels; he is on the strategic advisory panel of the GHC and his organisation, Save the Children, receives funding to support WHO with staffing and capacity building of health clusters in the field. RW worked for WHO during 1990-94 on secondment from CDC and subsequently has done several paid consultations for WHO in addition to having attended numerous conferences, meetings, and discussions. JL has been part of a WHO advisory group on research in humanitarian crises. EM has consulted for the WHO HIV department. MT has been a temporary adviser for WHO on several occasions, sometimes paid. BW reports personal fees from $\mathrm{WHO}$ and past frequent collaboration with WHO staff. AZ has done occasional consultancies over the past 20 years for WHO including one about a decade ago identifying suggested roles for WHO in emergencies.

Provenance and peer review: Not commissioned; externally peer reviewed.

Bruckner C, Checchi F. Detection of infectious disease outbreaks in twenty-two fragile states, 2000-2010: a systematic review. Confl Health 2011:5:13.

2 Baize S, Pannetier D, Oestereich L, et al. Emergence of Zaire Ebola virus disease in Guinea. N Engl J Med 2014;371:1418-25.

3 Boseley S. World Health Organisation admits botching response to Ebola outbreak. Guardian 2014 Oct 17. www.theguardian.com/world/2014/oct/17/world-health-organisationbotched-ebola-outbreak.

4 Gostin LO, Friedman EA. A retrospective and prospective analysis of the west African Ebola virus disease epidemic: robust national health systems at the foundation and an empowered WHO at the apex. Lancet 2015;385:1902-9.

5 Cheng M, Satter R. Emails: UN health agency resisted declaring Ebola emergency. Associated Press, 20 Mar 2015. http://bigstory.ap.org/article/ ea7199795faa48989449131404b7043e/emails-un-health-agency-resisted-declaring-ebolaemergency.

6 World Health Organization. Ebola situation report-23 September 2015. 2015. http://apps. who.int/ebola/current-situation/ebola-situation-report-23-september-2015.

7 Evans DK, Goldstein M, Popova A. Health-care worker mortality and the legacy of the Ebola epidemic. Lancet Glob Health 2015;3:e439-40.

8 Mullan Z. The cost of Ebola. Lancet Global Health 2015;3:e423.

9 Gostin LO, Sridhar D, Hougendobler D. The normative authority of the World Health Organization. Public Health 2015;129:854-63.
10 Sridhar D, Frenk J, Gostin L, Moon S. Global rules for global health: why we need an independent, impartial WHO. BMJ 2014:348.g3841.

11 DuBois M, Wake C, Sturridge S, Bennett C. The Ebola response in west Africa: Exposing the politics and culture of international aid. Overseas Development Institute. 2015. www. odi.org/sites/odi.org.uk/files/odi-assets/publications-opinion-files/9903.pdf. (accessed 25 November 2015), 2015.

12 Horton R. Offline: a pervasive failure to learn the lessons of Ebola. Lancet 2015;386:1024.

13 Moon S, Sridhar D, Pate MA, et al. Will Ebola change the game? Ten essential reforms before the next pandemic. The report of the Harvard-LSHTM independent panel on the global response to Ebola. Lancet 2015 Nov 20.

14 Ebola Interim Assessment Panel. Report of the Ebola interim assessment panel. 2015. www.who.int/csr/resources/publications/ebola/report-by-panel.pdf.

15 World Health Organization. Governing body documentation: official records-governance. 2015. http://apps.who.int/gb/.

16 Gostin LO, Friedman E, Hougendobler E. Briefing paper No 11. Ebola, the World Health Organization, and beyond: toward a framework for global health security. O'Neill Institute for National and Global Health Law, 2015. www.law.georgetown.edu/oneillinstitute/ resources/documents/Briefing11GlobalHealthSecurity.pdf.

17 World Health Organization Executive Board. Executive board special session on the Ebola emergency. Resolution EBSS/3/2015/REC/1. 2015. http://apps.who.int/gb/ebwha/pdf_ files/EBSS3-REC1/EBSS3_REC1.pdf\#page $=12$.

18 World Health Organization. Advisory group on reform of WHO's work in outbreaks and emergencies with health and humanitarian consequences. 2015. www.who.int/about/who reform/emergency-capacities/advisory-group/en/.

19 Fink-Hooijer F. Civil protection and humanitarian aid in the Ebola response: lessons for the humanitarian system from the EU experience. Humanitarian Exchange 2015;64:3-5.

20 Heymann DL, Chen L, Takemi K, et al. Global health security: the wider lessons from the west African Ebola virus disease epidemic. Lancet 2015;385:1884-901.

21 Centre for Research on the Epidemiology of Disasters. The human cost of natural disasters 2015: a global perspective. 2015. http://cred.be/sites/default/files/The_Human_Cost_of Natural_Disasters CRED.pdf.

22 Centre for Research on the Epidemiology of Disasters. People affected by conflict 2013 : humanitarian needs in numbers. 2013. http://cred.be/download/download.php?file=sites/ default/files/PAC2013.pdf.

23 Spiegel PB, Le P, Ververs MT, Salama P. Occurrence and overlap of natural disasters, complex emergencies and epidemics during the past decade (1995-2004). Confl Health 2007;1:2.

24 World Health Organization. Health and mortality survey among internally displaced person in Gulu, Kitgum and Pader Districts, northern Uganda. 2005. www.who.int/hac/crises/uga/ sitreps/Ugandamortsurvey.pdf.

25 Checchi F. Humanitarian interventions in northern Uganda: based on what evidence? Humanitarian Exchange 2006;36:7-11.

26 Vasagar J. Mugabe defends razing of shanty towns. Guardian 2005 June 10. www. theguardian.com/world/2005/jun/10/zimbabwe.jeevanvasagar.

27 Action Aid. An in-depth study of the impact of Operation Murambatsvina / Restore Order in Zimbabwe. 2005. www1.umn.edu/humanrts/research/ZIM\%20ACTION\%20AID-Making\% 20Life\%20Unbearable.pdf.

28 Salignon P. Sri Lanka behind closed doors. Humanitarian practice network blog and articles: the humanitarian space, 29 Oct 2009. http://reliefweb.int/report/sri-lanka/sri-lankabehind-closed-doors.

29 Independent Monitoring Board of the Global Polio Eradication Initiative. Eighth report-October 2013. www.polioeradication.org/portals/0/document/aboutus/governance/ imb/9imbmeeting/9imb_report_en.pdf.

30 Sahloul Z, Coutts A, Fouad FM, et al. Health response system for Syria: beyond official narrative. Lancet 2014;383:407.

31 Asgary R. Direct killing of patients in humanitarian situations and armed conflicts: the profession of medicine is losing its meaning. Am J Trop Med Hyg 2015;92:678-80.

32 World Health Organization. Emergency response framework. 2013. www.who.int/hac/ about/erf_.pdf.

33 Lee K, Pang T. WHO: retirement or reinvention? Public Health 2014;128:119-23.

34 WHO's African regional office must evolve or die. Lancet 2004;364:475-6.

35 Calain P, Abu Sa'Da C. Coincident polio and Ebola crises expose similar fault lines in the current global health regime. Confl Health 2015;9:29.

36 Clift C. Chatham House report: what's the World Health Organization for? Chatham House, 2014. www.chathamhouse.org/sites/files/chathamhouse/field/field_document/ 20140521WHOHealthGovernanceClift.pdf.

37 Clift C. WHO Ebola report is a missed opportunity. Chatham House, 2015. www. chathamhouse.org/expert/comment/who-ebola-report-missed-opportunity.

38 Sphere Project. Sphere handbook. 2011. www.sphereproject.org.

39 Tan YS, von Schreeb J. Humanitarian assistance and accountability: what are we really talking about? Prehosp Disaster Med 2015;30:264-70.

40 Hanrieder T. The path-dependent design of international organizations: Federalism in the World Health Organization. Eur J Int Relations 2015;21:215-39.

41 Godlee F. The World Health Organisation. The regions-too much power, too little effect. BMJ 1994;309:1566-70.

42 Boseley S. How WHO revised its self-criticism over Ebola handling. Guardian 2015 Apr 20. www.theguardian.com/society/sarah-boseley-global-health/2015/apr/20/how-whorevised-its-self-criticism-over-ebola-handling.

43 Yamey G. WHO's management: struggling to transform a "fossilised bureaucracy." BMJ 2002;325:1170-3.

44 How is WHO responding to global public health threats? PLoS Med 2007:4:e197.

45 Advisory Group on Reform of WHO's Work in Outbreaks and Emergencies. First report. 2015. www.who.int/about/who_reform/emergency-capacities/first-report-advisory-group. pdf?ua=1.

46 Brown TM, Cueto M, Fee E. The World Health Organization and the transition from "international" to "global" public health. Am J Public Health 2006;96:62-72.

47 World Health Organization. Report of the review committee on the functioning of the International Health Regulations (2005) in relation to the pandemic (H1N1). 2009. http:// apps.who.int/gb/ebwha/pdf_files/WHA64/A64_10-en.pdf.

48 Godlee F. WHO reform and global health. BMJ 1997;314:1359-60.

49 Office of the United Nations Special Envoy on Ebola. Resources for results IV: 1 September 2014 to 31 May 2015. UNMEER, 2015. http://ebolaresponse.un.org/sites/default/files/ resources_for_results_iv.pdf.

50 Rutter PD, Donaldson LJ. Oversight role of the independent monitoring board of the global polio eradication initiative. J Infect Dis 2014;210(suppl 1):S16-22. 
51 Goma Epidemiology Group. Public health impact of Rwandan refugee crisis: what happened in Goma, Zaire, in July, 1994? Lancet 1995;345:339-44.
Cite this as: $B M J 2016 ; 352: 1469$ 


\section{Table}

\section{Table 1/ Six proposals for WHO reform*}

Proposal and specific actions or changes

Internal restructuring and streamlining, with external governance

Merge the emergency/humanitarian (polio and emergencies) and epidemic/pandemic
(health security) divisions into a single all hazards crises division (this is now in process at WHO headquarters). Reproduce the same crisis response structure at all levels of the organisation

Bring coordination of the Global Health Cluster, Global Outbreak Alert and Response Network, emergency medical teams, and other partnerships under a single team within the above department, merging equivalent functions

For an initial period (five years), make the crisis department dually accountable to the Problems with current structure director general and to an external, independent civil society governance committee, modelled on the independent monitoring board of the Global Polio Eradication Initiative, and empowered to make strategy, funding, work planning, and hiring decisions (similar to the arrangement proposed by the German chancellor, Angela Merkel)

\section{Radical human resources review and reinforcement of meritocratic policies}

Establish procedures for rapid hiring and induction of emergency staff, minimising existing human resources bottlenecks

Institute a robust system of performance management with clear pathways for excellent and sub-par performers and proactive talent identification. Involve external appraisers in the performance management of senior posts, based on concrete evidence of effectiveness

Commission an externally led review of existing senior and middle management role holders in key positions involved with emergency management (including country representatives in crisis-prone countries) against the emergency competency framework, with a view to upgrading skills where required and discontinuing contracts if necessary

Enforce a moratorium on all political appointments. Hire competitively all positions at all levels of the organisation, according to the "fit for purpose" principle

\section{Increased capacity to manage crises through coordination and leadership} Develop a greatly enhanced professional cohort of emergency coordinators, information
managers/epidemiologists and public health advisers with readiness to deploy into coordination or response management roles. This pool can sit within WHO or be distributed among partner agencies but should be financially underwritten to guarantee duration of contract and availability for surge deployments, and undergo the same learning and development steps based on common protocols and tools

Define key competencies (eg, leadership, risk taking, management, influencing, effective communications), and technical skills required of non-emergency dedicated staff (country representatives, other technical specialists in country offices) to repurpose their work in times of crisis; ensure these staff undergo learning and professional development to acquire these competencies and skills

(Note that various concepts for a so called global health emergency workforce led by WHO have been put forward. Our proposal is that WHO should focus on establishing skilled teams for leadership and coordination, not for actual operations)

\section{Increased focus on setting sector standards and improving public health practice in crisis settings}

Expand and repurpose WHO's technical team in the new crises division, while also drawing on specialties and skills present in partner agencies and academic centres of excellence, so as to:

(i) review and update technical standards and competency frameworks for health services and staff in crisis settings

(ii) set up and deliver sufficiently scaled headquarters and field based capacity building programmes for humanitarian agencies, adherent to these standards

(iii) set up a programme for ongoing certification of health agencies and staff as fit to operate in different crisis contexts. The emergency medical team model could be a good foundation for such a programme

\section{Step aside arrangements for emergencies}

Predefine country offices that fulfil minimal criteria for being able to lead and manage Prioritisation of political over responses to all hazards. For any emergency in countries that do not meet these criteria, technical considerations as well as whenever responses meet certain size triggers (eg, level 3 ) or are not being managed adequately locally, automatically shift responsibility for crisis management to an emergency team deployed from headquarters, reporting to the crisis division and managing relevant country office emergency staff

\section{Problem(s) tackled}

Expected challenges/risks

Aloofness from civil society partners and neglect of sector coordination and leadership functions

Lack of internal and external

accountability Internal resistance, restructure fatigue

Initial confusion of roles and responsibilities (internal and external)

Transactional costs
Prioritisation of political over technical considerations

A non-meritocratic human resources approach, with little

reference to crisis response

competencies

Lack of internal and externa

accountability

A non-meritocratic human resources crisis response competencies

Aloofness from civil society partners and neglect of secto functions

Insufficient flexible funding for crisis functions
Aloofness from civil society partners and neglect of sector coordination and leadership functions
Dependent on establishment of fit for purpose human resource procedures (see above) Costs of salaries, professional development and deployment costs

Internal resistance and conflict

\section{Staff demotivation}

Transactional costs

Damage to government relations

External resistance by humanitarian agencies

Conflict with other inter-agency standard-setting initiatives
Increased friction between country, regional and headquarters teams 
(continued)

Proposal and specific actions or changes

Problem(s) tackled

Expected challenges/risks

All cluster coordination teams to be appointed and managed directly from headquarters

Specify the above arrangements as mandatory in a revised WHO emergency response framework and clarify the roles of headquarters, regional, and country offices

\section{Enhanced transparency and open performance monitoring}

Establish an independent pool of experienced public health and health systems evaluators/researchers who can be mobilised at the time of emergencies and immediately afterwards

Undertake systematic and structured evaluations of WHO responses to emergencies,

with scope dependent on the importance of the response (eg, UN level of the emergency),

commissioned by the external governance board (proposed above) to a non-UN

independent evaluation team (see above), measuring performance against key standards, identifying key weaknesses and proposing modifications

Ensure open publication of each evaluation, making it clear which WHO teams were
$\begin{aligned} & \text { accountable for the response being evaluated, what actions have been agreed to internal and external } \\ & \text { address recommendations of the evaluation, and who is responsible for implementing } \\ & \text { these actions }\end{aligned}$

*Some of the proposals described here are similar to those made by the executive board and other groups. ${ }^{11} 1314$ 